\title{
NOTAS PARA PENSAR O SUJEITO: GEOGRAFIA HUMANISTA COM DELEUZE E GUATTARI
}

\author{
Notes to Think the Subject: Humanist Geography with Deleuze e Guattari \\ Notas para Pensar el Sujeto: Geografía Humanista con Deleuze e Guattari
}

Ivo VeNEROTTI GUIMARÃeS

VIVIANA RIBEIRO

\begin{abstract}
Resumo: Na década de 1970, os estudos em geografia passaram por uma virada humanista. Levando em consideração o contexto dessa década, chama a atenção que, dentre as aproximações empreendidas com a filosofia, o pensamento francês pós-1960 não tenha sido considerado. Este ensaio, portanto, abarca um desafio, qual seja o de pensar a geografia humanista em suas aberturas, estreitando o diálogo com outras filosofias que também possam animá-la. No momento, apenas indicamos algumas notas de um estudo em andamento cujo esforço centra-se em pensar a geografia humanista com Deleuze e Guattari para abordar o sujeito, entendendo que "há toda uma geografia nas pessoas". Acreditamos que tal aproximação teria implicação direta para a maneira de se conceber a experiência e, por conseguinte, para o conceito de lugar.
\end{abstract}

Palavras-chave: Sujeito; Geografia humanista; Deleuze e Guattari.

Resumen: En la década de 1970, los estudios en geografía pasaron un turno humanista. Teniendo en cuenta el contexto de esa década, hay que destacar que entre las apoximaciones adoptadas con la filosofía, el pensamiento francés posterior a 1960 no se ha considerado. Por lo tanto, este ensayo abarca um desafío, que es pensar la geografía humanista en sus aberturas, intensificando el diálogo con otras filosofías que también pueden animarla. Por el momento, sólo indicamos algunas notas de un estudio en curso cuyo esfuerzo se centra en pensar la geografía humanista con Deleuze y Guattari para discutir el sujeto, entendiendo que "en las personas hay toda uma geografia". Creemos que este enfoque podría tener implicaciones directas para el modo de concebir la experiencia y por tanto al concepto de lugar.

Palabras-clave: El sujeto; La geografía humanista; Deleuze y Guattari.

Abstract: In the 1970s, studies in geography went through a humanist turn. Taking into account the context of that decade, it is noteworthy that among the approaches undertaken with the philosophy, the post-1960 French thought has not been considered. This academic essay, therefore, faces a challenge, which is to think the humanist geography in their openings, strengthening dialogue with other philosophies that also animate it. At this moment, we only indicate some notes of an ongoing study whose effort focuses on thinking humanist geography with Deleuze and Guattari to discuss the subject, understanding that "there is a whole geography in people". We believe that such an approach would have direct implications for the way to conceive experience and hence to the concept of place.

Keywords: Subject; Humanist geography; Deleuze and Guattari.

\section{Introdução}

Na década de 1970, os estudos em geografia passaram por uma virada humanista ${ }^{1}$. Geógrafos que sentiam a sufocante ausência do homem nos estudos geográficos, por demais endurecidos, estatísticos e positivistas, viram nas filosofias do significado um solo fértil de ideias para criação de uma nova forma de pensar geograficamente,

\footnotetext{
1 Vale mencionar a obra de Eric Dardel (1952/2011), na qual podemos encontrar, em sua bibliografia, menção a autores ligados a fenomenologia ou preocupados com formulação de um outro humanismo. Podemos citar Bachelard, Heidegger, Jaspers, Lévinas, Merleau-Ponty, Ricoeur e Sartre, por exemplo. Em que pesem o ineditismo e originalidade do texto, seus escritos não chegaram a provocar um movimento na geografia quando publicados, sendo redescobertos justo na década de 1970 por geógrafos que tiveram participação na virada humanista (HOLZER, 2001).
}

onde o homem não se apresentaria mais como elemento dispensável, mas, ao contrário, estaria completamente inserindo no espaço (Holzer, 1992; Mello, 1991). Para a geografia em sua vertente humanista não apenas o homem, mas também a experiência ganha relevante importância, sendo que esta última pode ser entendida como um campo onde os símbolos, as identidades, as imagens e as imaginações se manifestam.

Dito isto, Holzer (1992), aponta o ano de 1976 como o de reconhecimento, pela academia norte-americana, da geografia humanista como campo autônomo, mencionando os trabalhos seminais de Yi-Fu Tuan (1976), Anne Buttimer (1976) e Edward Relph (1976). O primeiro com o artigo "Humanistic Geography", a segunda com "Grasping the dynamism of lifeworld", ambos publicados no Annals of the Association of American Geographers, e o 
terceiro com o livro "Place and Placelessness", acabaram por consolidar as discussões que vinham ocorrendo durante a década de 1970. Nessas mencionadas publicações, a aproximação com a filosofia é evidente, sobretudo com a fenomenologia (em diálogo com autores como Husserl, Heidegger, Merleau-Ponty, entre outros), haja vista que o geógrafo humanista, como nos afirma Tuan (1976), deve estar capacitado em filosofia.

Levando em consideração o contexto da década de consolidação do horizonte humanista em geografia, chama a atenção que, dentre as aproximações empreendidas com a filosofia, o pensamento francês pós-1960 não tenha sido considerado. Filósofos como Gilles Deleuze, Michel Foucault e Jaques Derrida, ${ }^{2}$ só para citar alguns, tinham suas obras largamente difundidas na América do Norte e no mundo anglófono em geral. Longe de nosso interesse investigar o cerne dessa questão, procuramos contribuir com a geografia humanista promovendo outros encontros, mais especificamente com Deleuze e Guattari. Diante disso, uma indagação se instala: se algumas vertentes da geografia humanista buscaram nas filosofias do significado, principalmente a fenomenologia para, em outras bases, criar novos conceitos de lugar e de experiência, quais seriam as implicações para a matriz geográfica humanista se pensarmos com Deleuze e Guattari?

Assim, devemos dizer que este ensaio, ao invés de responder a pergunta acima, assume sua condição de nota de pesquisa, ao apontar caminhos possíveis em um estudo em andamento.

\section{Filosofia francesa contemporânea: crise e novos temas}

Para os historiadores de filosofia contemporânea Christian Delacampagne e Christian Descamps, a filosofia francesa do século XX irrompe de uma crise iniciada no final do século XIX, momento em que grandes paradigmas foram colocados em dúvida. A verdade, a existência de Deus, a validade do pensamento como representação, a existência de signos confiáveis e a ideia de que a atividade da mente estaria de pleno acordo com o mundo, passaram a ser interrogados (Delacampagne, 1995/1997; Descamps, 1985/1991). Esta crise, que se apresentou de maneira mais ampla como crise da modernidade, se alastrou para literatura, música, pintura e também para as ciências, especialmente a matemática. Na filosofia, ela não significou apenas um questionamento dos conceitos

\footnotetext{
2 Embora tenha se convencionado a enquadrar essa geração de pensadores franceses com produção filosófica intensa a partir da década de 1960 como pós-estruturalistas, não concordamos com tal denominação. Tal grupo, criação da academia estadunidense, com representantes tão próximos e distantes quanto, por exemplo, Deleuze, Foucault, Derrida, Jaques Lacan e Louis Althusser não compuseram um grupo comum, com linhas de pesquisa afins, nem tinham a intensão de formar uma escola de pensamento. Sendo assim, não há pós-estruturalismo na França, termo forjado para recepção americana, tendo essa nomenclatura se propagado internacionalmente (ANGERMULLER, 2015)
}

e dos seus fundamentos, mas também uma problematização profunda do próprio ato de pensar, sua forma e seus instrumentos metodológicos.

Alain Badiou, em "A Aventura da Filosofia Francesa no século XX" (2015), compreende que há no período iniciado a partir das décadas de 1950/1960 até o momento, questões programáticas e compartilhadas que afetam toda a produção de pensamento deste período e tais questões se desenvolvem em torno de dois temas centrais: o sujeito e modificações nas operações metodológicas do pensamento. A partir dessas duas grandes questões centrais, a filosofia contemporânea vem estabelecendo seus debates internos com a herança cartesiana e a herança alemã (Hegel, Husserl e Heidegger, mas também Marx e Nietzsche), bem como não cessa de realizar seus movimentos externos ao dialogar com a psicologia, a política, a literatura e as artes em geral.

Desta feita, segundo Badiou, para pensar em novas constituições subjetivas (alternativa ao cartesianismo e ao kantismo), preocupada em pensar em novos sujeitos de ação (aspecto político e prático) e outros modos de existência (aspecto ético), a filosofia contemporânea francesa se volta para pintura não figurativa, a nova música, o teatro, o romance policial, o jazz e o cinema. Contagiada pela literatura, a filosofia contemporânea se colocaria a pensar novas maneiras de engendrar o pensamento e uma nova escrita para dizer um novo sujeito:

Dessa nova escrita, trata-se de dizer o novo sujeito, de criar, na língua, a nova figura do sujeito. Porque o sujeito moderno, o último engajamento do movimento filosófico francês, não pode ser o sujeito racional e consciente vindo diretamente de Descartes; nem pode ser, para dizer mais tecnicamente, o sujeito reflexivo; ele deve ser algo mais obscuro, mais ligado à vida, ao corpo, um sujeito menos estreito do que um sujeito consciente, alguma coisa que é como uma produção ou uma criação, concentrado nela forças mais vastas. Que ela adote, que ela retome a palavra "sujeito", ou que ela a destitua em proveito de outros vocábulos, é isso que a filosofia francesa tenta dizer, encontrar e pensar. (Badiou, 2015, p. 15)

Este ensaio, portanto, abarca um desafio, qual seja o de pensar a geografia humanista em suas aberturas, estreitando o diálogo com outras filosofias que também possam animá-la. No momento, apenas indicamos algumas notas de um estudo em andamento cujo esforço centra-se na aproximação da geografia humanista com o pensamento de Deleuze e Guattari para pensar o sujeito e, em nosso entender, tal aproximação teria implicação direta para a maneira de se conceber a experiência e, por conseguinte, para o conceito de lugar.

Não se pode negar que ao pensar o lugar em sua relação com os indivíduos e grupos sociais, introduzindo o campo experiencial nos termos da virada humanista em geografia, estão implícitas aí outras formas de se entender o sujeito. Dizemos implícito porque o tópico foi 
pouco abordado de forma direta - o que demanda, inclusive, uma cartografia do assunto em geografia. Trata-se de uma discussão necessária, conforme apontam os geógrafos Sartre e Berdoulay (2005), Berdoulay e Entrikin (1998/2012), Lima (2013), além de ser umas das preocupações daqueles ligados à pós-fenomenologia bem como dos que se encontram associados a pensadores europeus pós-1960, sobretudo os franceses (Marandola Jr., 2013). Dessa maneira, a pesquisa empreende um esforço de se debruçar sobre o tema do sujeito na geografia, levando em consideração afetos e devires, tais como os entendem Deleuze e Guattari (1980/1997).

\section{2. "Há toda uma geografia nas pessoas"}

Deleuze e Claire Parnet, no livro Diálogos dizem o seguinte:

(...) as coisas, as pessoas são compostas por linhas muito diversas, e que não sabem, necessariamente, em que linhas estão, nem onde fazer passar a linha que estão em vias de traçar; numa palavra: há toda uma geografia nas pessoas, com linhas duras, linhas flexíveis, linhas de fuga, etc. (Deleuze \& Parnet, 1977/2004, p. 21 - grifo nosso)

O que Deleuze quer dizer por "há toda uma geografia nas pessoas"? O trecho parece indicar, antes de tudo, uma maneira de se compreender "pessoa" como algo constituído por linhas. Na mesma esteira, Deleuze e Guattari formulam:

(...) somos feitos de linhas. Não queremos apenas falar de linhas de escrita; estas se conjugam com outras linhas, linhas de vida, linhas de sorte ou de infortúnio, linhas que criam a variação da própria linha de escrita, linhas que estão entre as linhas escritas. (Deleuze \& Guattari, 1980/2012, p. 72)

\section{E mais adiante:}

Indivíduos ou grupos, somos atravessados por linhas, meridianos, geodésias, trópicos, fusos, que não seguem o mesmo ritmo e não tem a mesma natureza. São linhas que nos compõem, diríamos três espécies de linhas. Ou antes, conjuntos de linhas, pois cada espécie é múltipla. Podemos nos interessar por uma dessas linhas mais do que por outras, e talvez, com efeito, haja uma que seja, não determinante, mas que importe mais do que as outras...se estiver presente. Pois, de todas essas linhas, algumas nos são impostas de fora, pelo menos em parte. Outras nascem um pouco por acaso, de um nada, nunca se saberá por quê. Outras devem ser inventadas, traçadas, sem nenhum modelo nem acaso: devemos inventar nossas linhas de fuga se somos capazes disso, e só podemos inventá-las traçando-as efetivamente, na vida. (Deleuze e Guattari, 1980/2012, p. 83)

Os trechos acima citados podem ser encontrados em "Mil Platôs", impressionante empreendimento filosófico de Gilles Deleuze e Félix Guattari. No Platô 8 (a obra é composta por platôs, não por capítulos, como frisam logo de início), intitulado "1874 - Três novelas ou o que se passou?", os autores pensam com a literatura. Embora o título mencione três novelas, estão presentes no referido platô quatro novelas e um conto. Com as novelas "Na gaiola”, de Henry James, "O colapso", de F. Scott Fitzgerald, "História do abismo e da luneta", de Pierrette Fleutiaux, "A cortina carmesim", de Barbey d'Aurevilly e com um conto "Um jeitinho", de Guy de Maupassant, os filósofos desenvolvem o pensamento "somos todos constituídos por linhas". De acordo com os autores, as pessoas, indivíduos ou grupos e também as sociedades, são constituídos por linhas de segmentaridade dura ou molares, linhas de segmentaridade maleável ou moleculares e linhas de fuga.

As linhas de segmentaridade dura são as linhas das identidades, onde estão contidos os grandes elementos de constituição (dominante-hegemônica) de uma pessoa: classe social, raça, orientação sexual, estado civil. Os grandes binarismos irredutíveis estão presentes nesta linha endurecida, feita de segmentos bem determinados. "A vida não para de se engajar em uma segmentaridade cada vez mais dura e ressecada" (Deleuze \& Guattari, 1980/2012, p. 77).

Seguindo as trilhas de Deleuze e Guattari, pensemos também com a literatura. O livro Americanah, da escritora Chimamanda Nogozi Adichie, conta a história da personagem Ifemelu, uma nigeriana que passa doze anos estudando nos Estados Unidos e depois retorna para Lagos. Os 12 anos de Ifemelu nos Estados Unidos marcam, justamente, a transição da personagem entre o término da adolescência e a vida adulta; cria a história de uma vida de imigrante na América do Norte e suas relações inter-raciais e, ainda, fala sobre a emocionante e histórica vitória de Barack Obama como primeiro presidente negro dos Estados Unidos. Desta obra destacamos o trecho abaixo, em consonância com o que seriam essas linhas duras conforme conceituaram Deleuze e Guattari em "Entendendo a América para o Negro não Americano: o tribalismo americano":

Nos Estados Unidos, o tribalismo vai muito bem, obrigado. Existem quatro tipos: de classe, ideologia, região e raça. Em primeiro lugar, vamos ao de classe. É bem fácil. Ele separa os ricos dos pobres.

Em segundo lugar, o de ideologia. Os liberais e conservadores. Eles não apenas discordam em questões políticas, mas cada lado acha que o outro é malévolo. O casamento com uma pessoa da outra ideologia é desencorajado e, nas raras ocasiões em que acontece, é considerado espantoso. Em terceiro lugar, o de região. Entre Norte e Sul. Os dois lados lutaram numa guerra 
civil e as máculas dessa guerra persistem. Finalmente, os de raça. Existe uma hierarquia de raça nos Estados Unidos. Os brancos estão sempre no topo, especificamente os brancos, de família anglo-saxã e protestante, conhecidos como WASPS, e os negros sempre estão em um nível mais baixo, enquanto o que está no meio depende da época e do lugar (ou, como dizem aqueles versos maravilhosos: "Se você é um branco, tudo bem; se você é marrom, fique por aí; se você é negro, volte para casa!”). Os americanos presumem que todos vão compreender seu tribalismo. Mas demora um pouco para entendê-lo de fato. Quando eu estava na faculdade, tivemos um palestrante convidado e uma colega sussurrou para outra: "Meu Deus, que cara de judeu ele tem", e estremeceu, estremeceu de verdade. Como se ser judeu fosse um coisa ruim. Não entendi. Para mim, o homem era branco, não muito diferente da menina que falara aquilo. Judeu, para mim, era algo vago, bíblico. Mas aprendi rápido. Entenda, na hierarquia das raças dos Estados Unidos, os judeus são brancos, mas ficam um degrau abaixo dos brancos. Era um pouco confuso, porque eu conhecia uma menina de cabelo cor de palha e sardas que se dizia ser judia. Como os americanos sabiam quem era judeu? Como minha colega sabia que aquele homem era judeu? Li em algum lugar que as faculdades americanas costumavam perguntar aos candidatos qual era o sobrenome de sua mãe, para ter certeza de que não eram judeus, porque não os aceitavam. Era assim que se sabia? Pelo sobrenome das pessoas? Quanto mais tempo você passar aqui, mais vai entender. (Adichie, 2014, p. 201-202)

Pensamos que o extrato acima cria uma imagem adequada do conceito de linhas duras que seriam, portanto, a classe, ideologia, região e raça. Segmentos que atravessam e constituem as pessoas de maneira bem determinada e dura, e estão em toda parte:

(...) existe aí, como em cada um de nós, uma linha de segmentaridade dura em que tudo parece contável e previsto, o início e o fim de um segmento, a passagem de um segmento a outro. Nossa vida é feita assim: não apenas os grandes conjuntos molares (Estados, instituições, classes), mas as pessoas como elementos de um conjunto, os sentimentos como relacionamentos entre pessoas são segmentarizados, de um modo que não é feito para perturbar nem para dispersar, mas ao contrário para garantir e controlar a identidade de cada instância, incluindo-se aí a identidade pessoal. (Deleuze \& Guattari, 1980/2012, p. 73)

Porém, existe outra linha que os filósofos chamam de linhas de segmentaridade maleável ou molecular, que constituem as pessoas por segmentos menos localizáveis, mais fluidos, como "partículas que escapam dessas classes, desses sexos, dessas pessoas” (Deleuze \& Guattari,
1980/2012, p. 74). São nestes segmentos que ocorrem as desterritorializações. No que passa como fluxo entre as grandes categorias, sem se fixar naqueles grandes elementos identificadores. Na segmentaridade maleável correm fluxos com potencialidade de mudança. É uma linha de constituição de mudança da pessoa, ainda que ela venha a voltar a endurecer, desembocando na segmentaridade dura ou molar, novamente.

Podemos dizer que o apaixonamento está na linha de segmentaridade maleável, como um fluxo que atravessa e desterritorializa a pessoa estratificada conforme os elementos das segmentaridades duras. A experiência do apaixonamento é uma daquelas que pode fazer provocar a desterritorialização dos eixos pessoais-identitários e abrir um caminho potente de fluxos, ainda que, em algum momento a pessoa volte a endurecer, caindo, novamente, nas segmentaridades duras. Em nível macro, o próprio sistema capitalista é compreendido como coisa constituída por linhas de segmentaridade maleável, como fluxo em corrente constante, o que explicaria a sua sobrevivência por tantos séculos, apesar das crises (endurecimentos) que poderiam fazer ruir o sistema, caso ele não fosse capaz de se reconstruir em outras bases:

A grande política nunca pode manipular seus conjuntos molares sem passar por essas microinjeções, essas infiltrações que a favorecem ou que lhe criam obstáculos; e mesmo, quanto maiores os conjuntos, mais se produz uma molecularização das instâncias em que eles põem em jogo. (Deleuze \& Guattari, 1980/2012, p. 85)

Dito de outro modo, as linhas maleáveis são os fluxos que não cessam de passar, por baixo e entre as segmentaridades duras e suas estratificações e é justo aquilo que desterritorializa. São fissuras nas linhas de segmentaridade duras. Pontos em que tudo muda e não está fixo. Por fim, existem, ainda, as linhas de fuga que, em primeiro lugar, nada tem a ver com fuga. São linhas de desterritorialização absoluta, que não admite segmentaridades, pois, ao contrário, explode as outras duas linhas. É a linha de ruptura, de criação do novo, mas que também, traz em si, imanentemente, os perigos de autodestruição.

Nesse sentido, Deleuze e Guattari sempre mencionam os artistas suicidas, nos quais as linhas de fuga irrompem com tanta intensidade, numa desterritorialização absoluta, que da criação se atinge a destruição. Acerca das linhas de fuga, disseram os autores:

Quanto à linha de fuga, não seria esta inteiramente pessoal, maneira pela qual um indivíduo foge, por conta própria, foge às "suas responsabilidades", foge do mundo, se refugia no deserto, ou ainda na arte...etc. Falsa impressão. (...) as linhas de fuga, estas não consistem nunca em fugir do mundo, mas antes em fazê-lo fugir, como se estoura um cano, e não há sistema social que não fuja/escape por todas as extremidades, 
mesmo se seus segmentos não param de se endurecer para vedar as linhas de fuga. Não há nada mais ativo do que uma linha de fuga, no animal e no homem. E até mesmo a história é forçada a passar por isso, mais do que por "cortes significantes". A cada momento, o que foge em uma sociedade? É nas linhas de fuga que se inventam armas novas, para opô-las às armas pesadas do Estado, e "pode ser que eu fuja, mas ao longo da minha fuga, busco uma arma”. (Deleuze \& Guattari, 1980/2012, p. 85-86)

As três linhas não param de se misturar e o desenvolvimento da teoria das linhas é uma das maneiras de Deleuze \& Guattari formularem a ideia de que há toda uma geografia nas pessoas:

As linhas não querem dizer nada. É uma questão de cartografia. Elas nos compõem, assim como compõem nosso mapa. Elas se transformam e podem mesmo penetrar uma na outra. Rizoma. Certamente não tem nada a ver com a linguagem, é ao contrário da linguagem que deve segui-las, e a escrita que deve se alimentar delas entre as próprias linhas. Certamente não tem nada a ver com significante, com uma determinação de um sujeito pelo significante. É antes, o significante que surge no nível mais endurecido de uma dessas linhas, o sujeito que nasce do nível mais baixo. Certamente não tem nada a ver como uma estrutura, que sempre se ocupou apenas de pontos e de posições, de arborescências, e que sempre fechou um sistema exatamente para impedi-lo de fugir. (Deleuze \& Guattari, 1980/2012, p. 84)

Para Deleuze e Guattari não é uma estrutura, nem um significante, que define um sujeito, mas o sujeito é, ele próprio, resultado do nível mais endurecido dessa relação entre as linhas que não param de se cruzar. Recorrendo mais uma vez a uma imagem literária de Americanah, é marcante um trecho do livro em que a personagem Ifemelu diz:

O único motivo pelo qual você diz que a raça nunca foi um problema é porque queria que não fosse. Nós todos queríamos que não fosse. Mas isso é uma mentira. Eu sou de um país onde a raça não é um problema; eu não pensava em mim mesma como negra e só me tornei negra quando vim para os Estados Unidos. (Adichie, 2014, p. 315)

Eu só me tornei negra quando vim para os Estados Unidos. Mesmo uma linha de segmentaridade dura, linha da identidade que distingue as pessoas pela raça, é um fluxo variante e produz um sujeito. A pessoa negra, nos Estados Unidos é o resultado de uma linha em nível mais endurecido, uma linha de segmentaridade dura. Uma linha que constitui a pessoa no deslocamento, na mudança de lugar.

E, esta linha de segmentaridade dura, ainda determina uma série de ações desse sujeito constituído no desloca- mento, como podemos ver em um trecho ainda mais mordaz: se mostre ofendido, mesmo quando não tiver ideia do que está sendo dito; cumprimente outros negros como sinal de irmandade; se for homem, seja super tranquilo, não se irrite demais, ou alguém vai achar que está prestes a sacar uma arma, vejamos: em "Para outros negros não americanos: nos Estados Unidos você é negro, baby”:

Querido negro não americano, quando você escolhe vir para os Estados unidos, vira negro. Pare de argumentar. Pare de dizer que é jamaicano ou ganense. A América não liga. E daí se você não era negro no seu país? Está nos Estados Unidos agora. Nós todos temos nosso momento de iniciação na Sociedade dos Ex-crioulos. O meu foi numa aula da faculdade, quando me pediram uma visão negra de algo, só que eu não tinha ideia do que aquilo significava. Então, simplesmente inventei. Além do mais, admita, você diz: "eu não sou negro" só porque sabe que os negros são o último degrau na escada de raças americanas. E você não quer estar ali. Não negue. E se ser negro trouxesse todos os privilégios de ser branco? Você ainda diria "não me chame de negro, eu sou de Trinidad?” É, eu sabia que não. Você é negro, baby. E essa é a questão de se tornar negro: você tem de se mostrar ofendido quando palavras como "farofeiro" e "tiziu" são usadas de brincadeira, mesmo que não tenha a menor ideia do que está sendo dito - e, como você é um negro não americano, é provável que não saiba o que elas significam. (Na faculdade, um colega branco me perguntou se eu gostava de melancia. Eu disse que sim e outra colega disse: "Meu deus, que coisa racista”. Fiquei confusa e disse: “Espere, por quê?”). Quando outro negro te cumprimenta com a cabeça em um bairro de maioria branca, você tem de retribuir. Eles chamam isso de cumprimento negro. É uma maneira que os negros têm de dizer: "você não está sozinho, eu estou aqui também”. Ao descrever as mulheres negras que você admira, sempre use a palavra FORTE, porque, nos Estados Unidos, é isso que as mulheres negras devem ser. Se você for mulher, por favor, não fale o que pensa como está acostumada a fazer no seu país. Porque, nos Estados Unidos, mulheres negras de personalidade forte dão MEDO. E, se você for homem, seja supertranquilo, nunca se irrite demais, ou alguém vai achar que está prestes a sacar uma arma. Quando estiver vendo televisão e ouvir um "insulto racial" sendo usado, fique ofendido na mesma hora. Apesar de estar pensando: "Mas por que eles não me explicam o que exatamente foi dito?" Apensar de querer decidir sozinho o quão ofendido ficar, ou mesmo se está ofendido, ainda assim você precisa ficar muito ofendido. (Adichie, 2014, p. 239-240)

Entendemos que a imagem literária presente em Americanah, com destaque para o trecho acima, nos apresenta um lugar constituindo um sujeito. Um sujeito que se 
constitui no deslocamento - de Lagos aos Estados Unidos - e na sua permanência neste lugar, também atravessado e constituído por linhas.

\section{Fecho/Desfecho/Inconcluso}

Estamos falando de linhas que atravessam e constituem tanto os grupos quanto os indivíduos e analisá-las é, imediatamente, uma prática e uma política, quer se trate de um indivíduo, de um grupo ou de uma sociedade: (...) a prática não vem após a instalação dos termos e de suas relações, mas participa ativamente do traçado das linhas, enfrenta os mesmos perigos e as mesmas variações do que elas (Deleuze \& Guattari, 1980/2012, p. 85).

Neste ponto, uma explicação. O termo prática é recorrente na obra de Deleuze e Guattari. Diz respeito a uma filosofia prática, isto é, uma filosofia que implica na vida e pensa em novas maneiras de se relacionar, pensar, viver e sentir. Prática ou filosofia prática também pode ser entendida como o pensamento que pensa e implica na ética, ou seja, mais uma vez, em modos de vida. Eis aqui, possibilidades para se para entender o sujeito. Como é de se esperar em uma nota de pesquisa, não há conclusão, mas indicações em forma de questionamentos. Em perspectiva, pensar a experiência e o lugar. Nessa direção, a aproximação entre a geografia humanista e Deleuze e Guattari, provocam as seguintes perguntas: quais são suas linhas? Qual mapa você está fazendo e remanejando? Qual linha abstrata você traçará e a que preço para você e para os outros? Qual é sua própria linha de fuga? Você racha? Você se desterritorializa? Qual linha você interrompe, qual você prolonga ou retoma, sem figuras nem símbolos? (Deleuze \& Guattari, 1980/2012).

\section{Referências}

Adichie, C. N. (2014). Americanah (J. Romeu, Trad.). São Paulo: Companhia das Letras.

Badiou, A. (2015). A aventura da filosofia francesa no século $X X$. (A. Teixeira \& G. Iannini, Trad.). Belo Horizonte: Autêntica Editora.

Angermuller, J. (2015). Why there is no poststructuralism in France: the making of an intellectual generation. London: Bloomsbury.

Berdoulay, V. \& Entrikin, J. (2012). Lugar e sujeito: perspectivas teóricas. Em L. de Oliveira, E. Marandola Jr \& W. Holzer (Orgs.). Qual espaço do lugar? (p. 93-116). São Paulo: Perspectiva. (Originalmente publicado em 1998).

Buttimer, A. (1976). Grasping the dynamism of lifeworld. Annals of the Association of American Geographers, 66(2), 266-276.

Dardel, E. (2011). O homem e a terra: natureza da realidade geográfica (W. Holzer, Trad.). São Paulo: Perspectiva. (Orginalmente publicado em 1952).
Delacampagne, C. (1997). História da filosofia no século XX (L. Magalhães, Trad.). Rio de Janeiro: Jorge Zahar Ed. (Originalmente publicado em 1995).

Deleuze, G. \& Guattari, F. (2012). Mil Platôs: capitalismo e esquizofrenia 2, v. 3. São Paulo: Editora 34 (Originalmente publicado em 1980).

Deleuze, G. \& Guattari, F. (1997). Mil Platôs: capitalismo e esquizofrenia 2, v. 4. (S. Rolnik, Trad.). São Paulo: Editora 34 (Originalmente publicado em 1980).

Deleuze, G. \& Parnet, C. (2004). Conversações. Lisboa: Relógio d'água (Originalmente publicado em 1977).

Descamps, Christian (1991). As ideias filosóficas contemporâneas na França (1960-1985). Rio de Janeiro: Jorge Zahar (Originalmente publicado em 1985).

Holzer, W. (1992). A geografia humanista: sua trajetória de 1950 a 1990. (Dissertação de Mestrado). Universidade Federal do Rio de Janeiro, Rio de Janeiro.

Holzer, W. (2001). A geografia fenomenológica de Eric Dardel. Em R. L. A. Corrêa \& Z. Rosendahl (Orgs.), Matrizes da geografia cultural (p. 103-122). Rio de Janeiro: Ed. Uerj.

Lima, E. L. de. (2013). Encruzilhadas geográficas: notas críticas sobre a compreensão do sujeito em geografia. (Tese de Doutorado). Universidade Federal Fluminense, Niterói.

Marandola Jr., E. (2013). Fenomenologia e pós-fenomenologia: alternâncias e projeções do fazer geográfico humanista na geografia contemporânea. Geograficidade, 3(2), 49-64.

Mello, J. B. F. de. (1991). O Rio de Janeiro dos compositores da música popular brasileira 1928/1991: uma introdução à Geografia Humanística. (Dissertação de Mestrado). Universidade Federal do Rio de Janeiro, Rio de Janeiro.

Relph, E. (1976). Place and Placeness. London: Pion.

Sartre, X. A. de \& Berdoulay, V. (2005). Teoria do sujeito, geografia e desenvolvimento local. Novos Cadernos NAEA, $8(2), 109-124$.

Tuan, Yi-Fu (1976). Humanistic geography. Annals of the Association of American Geographers, 66(2), 266-276.

Ivo Venerotti Guimarães - Doutorando do Programa de Pós-graduação em Geografia da Universidade do Estado do Rio de Janeiro (PPGEO/ UERJ). Endereço Institucional: Rua Bolívar, 165, apto. 901, CEP: 22061 020, Rio de Janeiro - RJ. Email: ivo.venerotti@gmail.com

Viviana Ribeiro - Mestre em Filosofia do Programa de Pós-graduação em Filosofia da Universidade Federal Fluminense (PFI/UFF). Endereço Institucional: Rua Duquesa de Bragança, n. 75, apto. 301. CEP: 20540300. Rio de Janeiro - RJ. E-mail: vivianamribeiro@gmail.com

Recebido em 26.04.16 Primeira Decisão Editorial em 16.09.16 Aceito em 19.09.16 